\title{
The P239S palladin variant does not account for a significant fraction of hereditary or early onset pancreas cancer
}

George Zogopoulos • Heidi Rothenmund • Ayelet Eppel • Colleen Ash • Mohammad Reza Akbari • David Hedley • Steven A. Narod $\cdot$ Steven Gallinger

Published online: 24 May 2007

(C) Springer-Verlag 2007

Erratum to: Hum Genet (2007) 121:635-637

DOI 10.1007/s00439-007-0361-z

The name of the first author of this article should read George Zogopoulos instead of Zogopoulous.

The online version of the original article can be found under doi:10.1007/s00439-007-0361-z.

G. Zogopoulos $\cdot$ H. Rothenmund · C. Ash · S. Gallinger

Sam Minuk Cancer Genetics and Biomarker Laboratories,

Samuel Lunenfeld Research Institute, Toronto, Canada

G. Zogopoulos · H. Rothenmund · A. Eppel · S. Gallinger

Familial Gastrointestinal Cancer Registry,

Mount Sinai Hospital, Toronto, Canada

M. R. Akbari · S. A. Narod

Women's College Research Institute,

University of Toronto, Toronto, Canada

D. Hedley

Department of Medical Oncology and Hematology and Division of Experimental Therapeutics, Ontario Cancer Institute/Princess

Margaret Hospital, University of Toronto, Toronto, Canada

S. Gallinger $(\square)$

Mount Sinai Hospital, 600 University Avenue,

Room 1225, M5G 1X5 Toronto, ON, Canada

e-mail: sgallinger@mtsinai.on.ca 